\title{
Fluoride given the all clear
}

\section{Washington}

FLuORIDE, the water and toothpaste additive that has dramatically reduced tooth decay since the $1950 \mathrm{~s}$, does not cause cancer, US government officials said last week after the most comprehensive review* ever of health studies on the chemical. While the finding comes as little surprise - fluoride has been added to public water supplies for over three decades with apparently no ill effect - it may provide yet another example of the weakness of animal tests in determining human toxicity.

The only serious hint that fluoride might cause cancer in humans comes from a study with rats performed last year by the government's National Toxicology

*Review of Fluoriue Benefits and Risks, US Department of Health and Human Services, 1991.
Program. A few male rats that were given nearly one hundred times a typical human flouride exposure did show some statistically significant carcinogenic activity - a finding that the researchers who performed the study characterized as "equivocal". Some animal studies have found that excess fluoride can cause skeletal and tooth damage, but the report notes that sensitivity to fluoride varies widely between species, making these results difficult to apply to humans.

Although the report recommends seven further studies on humans and bacteria to set optimum dietary levels, among other objectives, its only suggestion concerning further animal carcinogenicity tests is that the government should "evaluate the scientific merit" of such studies.

Christopher Anderson

\section{Storm at Bangalore institute}

\section{New Delhi}

THE Raman Research Institute (RRI) in Bangalore, founded by the late Nobel laureate C. V. Raman, is passing through a crisis because of the treatment of 52year-old Professor C. V. Vishveshwara, a theoretical physicist of international repute. His abrupt sacking, followed by the renewal of his service contract "under impossible working conditions", has sparked off a controversy.

The reasons given for terminating Vishveshwara's contract are that he failed to attract bright young people, to guide a single student towards a $\mathrm{PhD}$ or to build a school in general relativity and gravitation, the field of his specialization. He was also informed by V. Radhakrishnan, the director of RRI, who is C. V. Raman's son, that his scientific work was just "acceptable", implying that it was not outstanding. But Vishveshwara was not told why the institute waited for 14 years to discover his deficiencies.

The eight-member RRI council, which manages the institute, is within its legal rights to terminate contracts without giving reasons. But Vishveshwara's case has aroused sympathy within the scientific community because of his international stature. One of the pioneers in black-hole physics and one of India's best-known relativists, he is next only to the director in seniority and is the only Asian elected to the Berne-based international society on general relativity and gravitation.

A student of Charles W. Misner, Vishveshwara joined RRI as an associate professor in 1976 and was made full professor in 1980 for a five-year term. His contract had been routinely renewed twice, but when the next renewal came up in September 1990, he was asked to quit. His well-wishers believe that the director's decision, later endorsed by the RRI council, smacked of jealousy and vindictiveness. Radhakrishnan, who has not made any comments, says he will respond at an appropriate forum.

Vishveshwara's case was all set to be closed, but the council was forced to reconsider the issue in the wake of a memorandum signed by some 200 scientists as well as by appeals from several of his collaborators in the United States and Europe. At its last meeting in December 1990 , the council agreed to renew the contract on condition that Vishveshwara would carry out only personal research in his field without interacting with other researchers at RRI.

The council also made it clear that the contract was being renewed "for extraneous reasons" and not on the merits of the case. Vishveshwara's room has also been moved from the physics block to the administrative block. Vishveshwara, who says that no self-respecting scientist would want to work under such humiliating conditions, has appealed against the "conditional" offer that his contract should be renewed.

At least one dissenting RRI council member has resigned, and several senior scientists, including nuclear physicist Raja Ramanna, have asked the president of the Indian Academy of Science, Professor C. N. R. Rao, to find a solution. A decision on Vishveshwara's appeal will be made at a special meeting of the Raman Trust, of which Rao is a member, on 2 March.

"Nothing that happened in the scientific community in recent years has disturbed it

\section{Halley at large}

COMEт Halley has made an unexpected reappearance in the night sky, following an unprecedented outburst of activity at its nucleus. Observers at the European Southern Observatory first noticed the outburst on 12 February, and confirmed that Comet Halley, now well beyond the orbit of Saturn, was the source. The cause of the outburst is a complete puzzle. Until last year, solar heating maintained a vestigial cloud of gas and dust around the comet's

\section{IMAGE UNAVAILABLE FOR COPYRIGHT REASONS}

Looking like just a faint smudge, Comet Halley has suddenly erupted into something at least 300,000 kilometres across. This image taken by 0 . Hainaut and A. Smetteon on 12 February, resembles those taken on subsequent nights, showing that Halley's reappearance is no flash in the pan.

nucleus. But now, the comet should consist solely of its dirty frozen nucleus. For it suddenly to take on the extended nebulous appearance observed by the European astronomers something must have made the nucleus erupt. A collision with another small body, interaction with solar wind and the sudden release of energy stored in the nucleus are possibilities entertained by astronomers. Roland Pease

as much as the unfortunate developments in RRI", said S. R. Valluri, a former member of the council and fellow of the Indian Academy of Science. Pointing out that the harassment of Vishveshwara signalled the "erosion of ethics of Indian science", Valluri resigned from the academy, describing this step as a "penance" for the acts of fellow members of the academy who served on the RRI council.

The government's Department of Science and Technology, which supports RRI, has adopted an ostrich-like attitude, saying it cannot interfere in the problems of an autonomous institute. But Valluri in his resignation letter observed that academic freedom did not prevail in RRI which, some of its scientists say, has become a family fiefdom of the Indian Nobel laureate.

K. S. Jayaraman 